Revista Perspectiva Online: Humanas \& Sociais Aplicadas Julho de 2017, Vol.7, n 19, p.10-22

ISSN: 2236-8876 (Online)

DOI: $10.25242 / 887671920171171$

\title{
TECNOLOGIA ASSISTIVA: INCLUSÃO EDUCACIONAL E SOCIAL
}

\author{
Juliana de Oliveira Barbosa Garrett ${ }^{1}$, Márcia Valéria dos Santo ${ }^{1}$, Teresa Claudina de Oliveira \\ Cunha $^{2 *}$ \& Vânia Machado Seabra Puglia ${ }^{3}$
}

\begin{abstract}
RESUMO
GARRETT, J. O. B.; SANTOS, M. V.; CUNHA, T. C. O. ; PUGLIA, V. M. S. Tecnologia Assistiva: Inclusão Educacional e Social. Perpectivas Online: Humanas \& Sociais Aplicadas, v.7, n.19, p.10-22, 2017.

Este artigo de revisão discorre sobre a primeira etapa do Projeto de Pesquisa "Tecnologia Assistiva: inclusão educacional e social". O objetivo deste artigo é o de apresentar os principais conceitos de Tecnologia Assistiva enquanto um facilitador para o processo de ensino e aprendizagem de alunos portadores de deficiências. Faz parte de um esforço para conhecer e apresentar conceitos, abordagens, objetivos, recursos, serviços, estratégias e práticas existentes no sentido de possibilitar a redução dos problemas funcionais encontrados pelos indivíduos portadores necessidades educativas

específicas. Para tanto se fez necessário um "mergulho" nas várias e infinitas possibilidades. É preciso pertencer, compartilhar, considerar e reconsiderar, investigar, examinar e descobrir o cenário histórico, as novas e renovadas perspectivas teóricas e metodológicas que possibilitam o conhecimento mais aprofundado sobre a questão a ser investigada. Para tanto de uma revisão de literatura, com o aporte teórico de consulta a livros que abordassem o tema objeto de estudo e periódicos selecionados por meio do banco de dados do Scielo e Mendeley, com publicação posterior ao ano 2006.
\end{abstract}

Palavras-chave: Tecnologia Assistiva. Educação Especial. Acessibilidade. 


\section{ABSTRACT}

This review article discusses about the first project of "Assistive Technology: Educational and Social Inclusion". The objective of this article is to present the main concepts of Assistive Technology as a facilitator for the teaching and learning process of students with disabilities. It is part of an effort to know and present concepts, approaches, objectives, resources, services, strategies and existing practices in the sense of enabling the reduction of functional problems encountered by individuals with specific educational needs. For this, a "dip" was necessary in the many and infinite possibilities. It is necessary to belong, to share, to consider and to reconsider, to investigate, to examine and to discover the historical scenario, the new and renewed theoretical and methodological perspectives that allow a more in depth knowledge about the question to be investigated. For This of a literature review, with the theoretical contribution of consultation to books that approached with the theme objective of study and selected newspaper through the database of Scielo and Mendeley, with publication after the year 2006

Keywords: Assistive Technology; Special education; Accessibility.

\footnotetext{
${ }^{1}$ Acadêmicas de Pedagogia ISECENSA- Institutos Superiores de Ensino do CENSA - ISECENSA - Rua Salvador Correa, 139, Centro, Campos dos Goytacazes, RJ, CEP: 28035-310, Brasil;

${ }^{2}$ Institutos Superiores de Ensino do CENSA - ISECENSA - Laboratório de Formação de Professor - Rua Salvador Correa, 139, Centro, Campos dos Goytacazes, RJ, CEP: 28035-310, Brasil.

${ }^{3}$ Institutos Superiores de Ensino do CENSA - ISECENSA - Rua Salvador Correa, 139, Centro, Campos dos Goytacazes, RJ, CEP: 28035-310, Brasil.

(*)e-mail: trcocunha@gmail.com

Data de chegada: 19/04/2017 Aceito para publicação: 09/06/2017
}

Persp. online: hum. \& sociais aplicada., Campos dos Goytacazes, 19 (7), 10-22, 2017

seer.perspectivasonline.com.br 


\section{INTRODUÇÃO}

A sociedade contemporânea conduz para um olhar mais profundo sobre a complexidade dos problemas tanto em nível nacional como internacional (a primazia cultural, as aspirações à individualização, a exigência a uma certa solidariedade, os imperativos éticos, a revolução tecnológica e comunicacional), desenha os contornos nos quais as sociedades, as organizações e indivíduos devem cada vez mais se inserir, se movimentar.

Uma sociedade que se caracteriza de forma marcante como sendo tecnocultural - tecnologia e comunicação. Comunicação representada principalmente pelos meios já conhecidos (rádio, televisão, jornais, redes sociais, etc.) e, as tecnologias caracterizadas, principalmente, pelas modernas e variadas formas comunicacionais do mundo tecnológico - ciberespaço, telecomunicações, os satélites de comunicação, as tecnologias de hipermídia ou do hipertexto que constituem a face mais visível desse momento denominado tecnocultura. Rede de significados, de sentidos possíveis, conexões diversas. O que muda, hoje, é que as operações são tecnológicas, onde cada um opera nesta rede com vários papéis. Segundo Muniz Sodré (1999, p. 9), "o mundo das máquinas é referência teórica e prática para o domínio da comunicação. As ciências da comunicação e da informação debruçam-se sobre os avanços tecnológicos, e estes são rapidamente convertidos em tecnologias do conhecimento, dispositivos capazes de produzir e transmitir comunicação".

Por meio de recursos tecnológicos, o mundo se povoa de imagem, mensagens, colagens, montagens, simulacros, virtualidades, objetos, aparelhos ou equipamentos eletrônicos, cada vez mais modernos e potentes, a seduzir com o sonho da libertação, da autonomia para a realização de infinitas atividades. Tecnologia pressupõe inovação, novos recursos, renovação, fazer e produzir o novo. Segundo o professor Claudio Kleina (2012, p. 27) a origem de toda inovação compreende a ideia de crescimento social. Para o autor a consequência da inovação tecnológica "deve ser tanto visível quanto mensurável, além de resultar em "alguma coisa boa" e que possua um "valor agregado", seja para o indivíduo, seja para o produto em questão, seja para o antigo processo, sempre que pelo menos um desses componentes constitua objetos de inovação".

Capovilla (1993, p. 138) ressalta que os recursos provenientes da tecnologia de comunicação e informação possibilitam o aperfeiçoamento "das interações entre pesquisadores, clínicos, professores, alunos e pais na área de Educação Especial", como exemplo pode-se citar os sistemas computadorizados de comunicação "que funcionam como porta-vozes eletrônicos, permitindo-lhes compor mensagens que podem ser impressas e soadas com voz, o mais semelhante possível à voz que tinham ou que deveriam ter" (p. 139), assim como os sistemas computadorizados de testes para a avaliação de habilidades cognitivas, de leitura e escrita, tais como o da Escala de Maturidade Mental Columbia, Teste de figuras invertidas computadorizado, Teste computadorizado de leitura silábica frente a vocábulos, etc. (p. 142-146)

Para Kleina (2012, p. 32) o uso da tecnologia na educação especial proporciona ao aluno a autonomia, "a possibilidade de demonstrar o seu potencial, aprender, interagir e participar ativamente em nossa sociedade". Afirma que muitos são os recursos e ferramentas tecnológicas que podem favorecer o aprendizado e desenvolvimento dos alunos com necessidades educacionais especiais. Conhecer esses recursos, assim como serviços, estratégias e práticas "que contribuem para proporcionar ou ampliar habilidades funcionais de pessoas com deficiência e consequentemente promover vida independente e inclusão" (BERSCH, 2013, p. 2) ainda se apresenta como um desafio para os profissionais da educação.

Importante destacar que em qualquer momento da escolaridade, um aluno pode apresentar uma necessidade específica educacional, dificuldades de aprendizagem. No entanto, conforme indica Carneiro (2015, p. 121), "há dificuldades e limitações, porém, que requerem meios e apoios mais especializados para o que o aluno possa acessar regularmente o currículo. Quando isso acontece, estamos diante de um aluno especial e a escola tem o dever de atender, adequadamente, suas necessidades educacionais especiais".

Neste artigo de revisão não se pretende fechar a questão, mas acima de tudo abrir um leque de questionamentos sobre o tema objeto de estudo. O objeto de trabalho - tecnologia assistiva, faz parte de um

Persp. online: hum. \& sociais aplicada., Campos dos Goytacazes, 19 (7), 10-22, 2017

seer.perspectivasonline.com.br 
esforço para conhecer e apresentar os modos pelos quais esta se processa - conceitos, abordagens, objetivos, recursos, serviços, estratégias e práticas existentes no sentido de possibilitar a redução dos problemas funcionais encontrados pelos indivíduos que se apresentam impedimentos seja por deficiências ou pelo envelhecimento. Para tanto se faz necessária um "mergulho" nos vários e infinitas possibilidades. É preciso pertencer, compartilhar, considerar e reconsiderar, investigar, examinar e descobrir o cenário histórico, as novas e renovadas perspectivas teóricas e metodológicas que possibilitem o conhecimento mais aprofundado sobre a questão a ser investigada.

Entende-se ser este um universo que envolve e produz inúmeros sentidos, possibilidades e desafios, para tanto, a pesquisa compreende etapas no processo de investigação. No primeiro momento, a pesquisa realizar-se-á uma explicação e uma interpretação simples, mas também exaustiva dos principais conceitos que fazem parte do universo da educação especial e da educação inclusiva, dos conceitos de tecnologia assistiva enquanto um facilitador para o processo de ensino e aprendizagem de alunos portadores de deficiências.

\section{METODOLOGIA}

Este artigo constitui-se de uma revisão de literatura, realizada entre setembro e março de 2017, com base em consulta a livros que abordassem o tema objeto de estudo e periódicos selecionados por meio do banco de dados do Scielo e Mendeley, com publicação posterior ao ano 2006.

\section{RESULTADOS E DISCUSSÃO}

\subsection{Da Educação Inclusiva}

Mais de um bilhão de pessoas em todo o mundo convivem com alguma forma de deficiência, dentre os quais cerca de 200 milhões experimentam dificuldades funcionais consideráveis. Segundo a Organização Mundial de Saúde (OMS, 2012), dados de 2011, revelam que 1 bilhão de pessoas vivem com alguma deficiência - isso significa uma em cada sete pessoas no mundo. Percebe-se que, ainda a ausência de estatísticas sobre pessoas com deficiência e isso, sem dúvida, contribui para a invisibilidade dessas pessoas. Isso representa um obstáculo para planejar e implementar políticas de desenvolvimento que melhorem a vida das pessoas com deficiência.

Segundo o Decreto n. 6.949, de 25 de agosto de 2009, pessoas com deficiência são aquelas que “[...] têm impedimentos de longo prazo de natureza física, mental, intelectual ou sensorial, os quais, em interação com diversas barreiras, podem obstruir sua participação plena e efetiva na sociedade em igualdades de condições com as demais pessoas". (BRASIL, 2009)

A Convenção Internacional sobre os Direitos das Pessoas (ONU) ressalta que "a deficiência resulta da interação entre pessoas com deficiência e barreiras comportamentais e ambientais que impedem sua participação plena e eficaz na sociedade de forma igualitária". A ONU alerta ainda que $80 \%$ das pessoas que vivem com alguma deficiência residem nos países em desenvolvimento. No total, 150 milhões de crianças (com menos de 18 anos de idade) tem alguma deficiência, segundo o UNICEF. Cerca de $30 \%$ dos meninos ou meninas de rua têm algum tipo de deficiência, e nos países em desenvolvimento $90 \%$ das crianças com deficiência não frequentam a escola.

No Brasil, os resultados do Censo Demográfico 2010 realizado pelo Instituto Brasileiro de Geografia e Estatística (IBGE, 2012, p. 114) apontaram que 23,9\% da população brasileira declaram ter pelo menos uma das deficiências investigadas. Dessas pessoas, 38.473 .702 se encontravam em áreas urbanas e 7.132.347, em áreas rurais. Segundo as professoras Rodrigues e Alves (2014, p. 172) esse percentual representa "um significativo aumento, se comparado aos $14,5 \%$ registrados no Censo de 2000 ".

Outro dado relevante apresentado pelo Censo de 2010 (Figura 1) indica que as taxas de alfabetização das pessoas com pelo menos uma das deficiências, com 15 ou mais anos de idade, não são uniformes entre as

Persp. online: hum. \& sociais aplicada., Campos dos Goytacazes, 19 (7), 10-22, 2017

seer.perspectivasonline.com.br 
regiões brasileiras. A Região Nordeste, que apresentou a maior taxa de prevalência de deficiência entre as regiões brasileiras, em torno de $26,6 \%$, teve a menor taxa de alfabetização, $69,7 \%$. Este percentual revela um valor bem infeiro ao da média nacional $(81,7 \%)$ e dos valores das regiões Sudeste e Sul, que apresentaram as maiores taxas, $88,2 \%$ e $88,1 \%$, respectivamente.

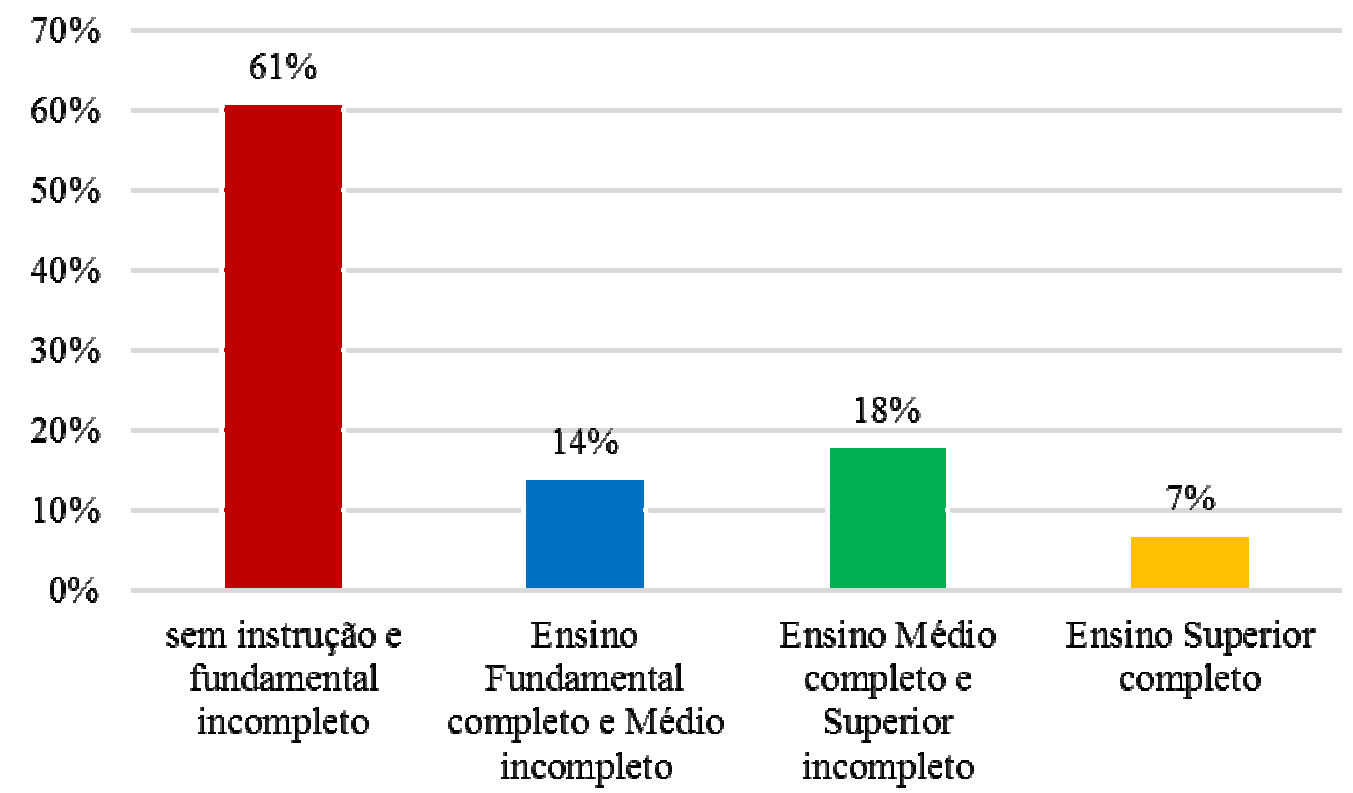

Figura 1: Pessoas com Deficiência, por grau de instrução

Fonte: Secretaria Especial dos Direitos da Pessoa com Deficiência. Disponível em:

$<$ http://www.pessoacomdeficiencia.gov.br/app/node/763>. Acesso em 10 nov. 2016.

Dentro da realidade da pessoa com deficiência, nota-se que o Brasil, vem ao longo do tempo, desenvolvendo algumas iniciativas (Políticas Públicas, Lei, Decretos, entre outras) para o enfrentamento da questão. O Quadro 1, apresenta um percurso nacional situando importantes marcos históricos e normativos voltados para a Educação Inclusiva no Brasil.

Quadro 1: Marcos históricos e normativos da Política Nacional de Educação Especial na Perspectiva da Educação Inclusiva no Brasil (BRASIL, 2008)

\begin{tabular}{|c|c|}
\hline Fundamentação Legal & Objetivos / Metas \\
\hline $\begin{array}{l}\text { Decreto } n^{\circ} 3.298 \text {, que regulamenta a Lei } n^{\circ} \\
7.853 / 89\end{array}$ & $\begin{array}{l}\text { Dispõe sobre a Política Nacional para a Integração da Pessoa } \\
\text { Portadora de Deficiência, define a educação especial como uma } \\
\text { modalidade transversal a todos os níveis e modalidades de } \\
\text { ensino, enfatizando a atuação complementar da educação } \\
\text { especial ao ensino regular. }\end{array}$ \\
\hline $\begin{array}{l}\text { Diretrizes Nacionais para a Educação } \\
\text { Especial na Educação Básica, Resolução } \\
\text { CNE/CEB n }{ }^{\circ} 2 / 2001\end{array}$ & $\begin{array}{l}\text { Os sistemas de ensino devem matricular todos os estudantes, } \\
\text { cabendo às escolas organizarem-se para o atendimento aos } \\
\text { educandos com necessidades educacionais especiais, } \\
\text { assegurando as condições necessárias para uma educação de } \\
\text { qualidade para todos. (MEC/SEESP, 2001) }\end{array}$ \\
\hline $\begin{array}{l}\text { Plano Nacional de Educação - PNE, Lei n } \\
10.172 / 2001\end{array}$ & $\begin{array}{l}\text { Estabelece objetivos e metas para que os sistemas de ensino } \\
\text { favoreçam o atendimento aos estudantes com deficiência, } \\
\text { transtornos globais do desenvolvimento e altas } \\
\text { habilidades/superdotação, aponta um déficit referente à oferta } \\
\text { de matrículas para estudantes com deficiência nas classes } \\
\text { comuns do ensino regular, à formação docente, à acessibilidade } \\
\text { física e ao atendimento educacional especializado }\end{array}$ \\
\hline
\end{tabular}

Persp. online: hum. \& sociais aplicada., Campos dos Goytacazes, 19 (7), 10-22, 2017

seer.perspectivasonline.com.br 


\begin{tabular}{|c|c|}
\hline Decreto $\mathrm{n}^{\circ} 3.956 / 2001$ & $\begin{array}{l}\text { Afirma que as pessoas com deficiência têm os mesmos direitos } \\
\text { humanos e liberdades fundamentais que as demais pessoas, } \\
\text { definindo como discriminação com base na deficiência toda } \\
\text { diferenciação ou exclusão que possa impedir ou anular o } \\
\text { exercício dos direitos humanos e de suas liberdades } \\
\text { fundamentais. }\end{array}$ \\
\hline $\begin{array}{l}\text { Resolução CNE/CP n }{ }^{\circ} 1 / 2002 \text { - Diretrizes } \\
\text { Curriculares Nacionais para a Formação de } \\
\text { Professores da Educação Básica, }\end{array}$ & $\begin{array}{l}\text { Define que as instituições de ensino superior devem prever, em } \\
\text { sua organização curricular, formação docente voltada para a } \\
\text { atenção à diversidade e que contemple conhecimentos sobre as } \\
\text { especificidades dos estudantes com deficiência, transtornos } \\
\text { globais do desenvolvimento e altas habilidades/superdotação }\end{array}$ \\
\hline Lei $\mathrm{n}^{\circ} 10.436 / 02$ & $\begin{array}{l}\text { Reconhece a Língua Brasileira de Sinais - Libras como meio } \\
\text { legal de comunicação e expressão, determinando que sejam } \\
\text { garantidas formas institucionalizadas de apoiar seu uso e } \\
\text { difusão, bem como a inclusão da disciplina de Libras como } \\
\text { parte integrante do currículo nos cursos de formação de } \\
\text { professores e de fonoaudiologia }\end{array}$ \\
\hline Portaria $n^{\circ} 2.678 / 02$ do MEC & $\begin{array}{l}\text { Aprova diretrizes e normas para o uso, o ensino, a produção e a } \\
\text { difusão do sistema Braille em todas as modalidades de ensino, } \\
\text { compreendendo o projeto da Grafia Braille para a Língua } \\
\text { Portuguesa e a recomendação para o seu uso em todo o } \\
\text { território nacional }\end{array}$ \\
\hline Programa Educação Inclusiva (2003) & $\begin{array}{l}\text { Prevê o direito à diversidade, com vistas a apoiar a } \\
\text { transformação dos sistemas de ensino em sistemas } \\
\text { educacionais inclusivos, promovendo um amplo processo de } \\
\text { formação de gestores e educadores nos municípios brasileiros } \\
\text { para a garantia do direito de acesso de todos à escolarização, à } \\
\text { oferta do atendimento educacional especializado e à garantia da } \\
\text { acessibilidade }\end{array}$ \\
\hline $\begin{array}{l}\text { Documento "O Acesso de Estudantes com } \\
\text { Deficiência às Escolas e Classes Comuns da } \\
\text { Rede Regular" (Ministério Público Federal - } \\
\text { 2004) }\end{array}$ & $\begin{array}{l}\text { Dissemina conceitos e diretrizes mundiais para a inclusão, } \\
\text { reafirmando o direito e os benefícios da escolarização de } \\
\text { estudantes com e sem deficiência nas turmas comuns do ensino } \\
\text { regular. }\end{array}$ \\
\hline Decreto $n^{\circ} 5.296 / 04$ & $\begin{array}{l}\text { Estabelecendo normas e critérios para a promoção da } \\
\text { acessibilidade às pessoas com deficiência ou com mobilidade } \\
\text { reduzida }\end{array}$ \\
\hline Decreto $\mathrm{n}^{\circ} 5.626 / 05$, & $\begin{array}{l}\text { Dispõe sobre a inclusão da Libras como disciplina curricular, a } \\
\text { formação e a certificação de professor de Libras, instrutor e } \\
\text { tradutor/intérprete de Libras, o ensino da Língua Portuguesa } \\
\text { como segunda língua para estudantes surdos e a organização da } \\
\text { educação bilíngue no ensino regular }\end{array}$ \\
\hline $\begin{array}{l}\text { Plano Nacional de Educação em Direitos } \\
\text { Humanos (2005) }\end{array}$ & $\begin{array}{l}\text { Objetiva, dentre as suas ações, contemplar, no currículo da } \\
\text { educação básica, temáticas relativas às pessoas com deficiência } \\
\text { e desenvolver ações afirmativas que possibilitem acesso e } \\
\text { permanência na educação superior }\end{array}$ \\
\hline $\begin{array}{l}\text { Plano de Desenvolvimento da Educação - } \\
\text { PDE (2007) }\end{array}$ & $\begin{array}{l}\text { Prevê a formação de professores para a educação especial, a } \\
\text { implantação de salas de recursos multifuncionais, a } \\
\text { acessibilidade arquitetônica dos prédios escolares, acesso e a } \\
\text { permanência das pessoas com deficiência na educação superior } \\
\text { e o monitoramento do acesso à escola dos favorecidos pelo } \\
\text { Benefício de Prestação Continuada - BPC }\end{array}$ \\
\hline Decreto $\mathrm{n}^{\circ} 6.094 / 2007$ & $\begin{array}{l}\text { Estabelece nas diretrizes do Compromisso Todos pela } \\
\text { Educação, a garantia do acesso e permanência no ensino } \\
\text { regular e o atendimento aos estudantes com deficiência, } \\
\text { transtornos globais do desenvolvimento e altas } \\
\text { habilidades/superdotação, fortalecendo seu ingresso nas escolas } \\
\text { públicas. }\end{array}$ \\
\hline
\end{tabular}

Persp. online: hum. \& sociais aplicada., Campos dos Goytacazes, 19 (7), 10-22, 2017

seer.perspectivasonline.com.br 


\begin{tabular}{|l|l|} 
Resolução CNE/CEB, 04/2009 & $\begin{array}{l}\text { Institui as Diretrizes Operacionais para o Atendimento } \\
\text { Educacional Especializado - AEE na Educação Básica }\end{array}$ \\
\hline Decreto $\mathrm{n}^{\circ} 7084 / 2010$ & $\begin{array}{l}\text { Dispõe sobre os programas nacionais de materiais didáticos, } \\
\text { estabelece no artigo 28, que o Ministério da Educação adotara } \\
\text { mecanismos para promoção da acessibilidade nos programas de } \\
\text { material didático destinado aos estudantes da educação especial } \\
\text { e professores das escolas de educação básica públicas }\end{array}$ \\
\hline Decreto $\mathrm{n}^{\circ} 7612 / 2011$ & $\begin{array}{l}\text { Plano Nacional dos Direitos da Pessoa com Deficiência - } \\
\text { Viver sem Limite }\end{array}$ \\
\hline $\begin{array}{l}\text { Lei no }{ }^{\circ} 13.005 / 2014, \text { que institui o Plano } \\
\text { Nacional de Educação - PNE, no inciso III, } \\
\text { parágrafo } 1^{\circ} \text {, do artigo } 8^{\circ}\end{array}$ & $\begin{array}{l}\text { Determina que os Estados, o Distrito Federal e os Municípios } \\
\text { garantam o atendimento as necessidades específicas na } \\
\text { educação especial, assegurado o sistema educacional inclusivo } \\
\text { em todos os níveis, etapas e modalidades }\end{array}$ \\
\hline
\end{tabular}

Fonte: Política Nacional de Educação Especial na Perspectiva da Educação Inclusiva, MEC/SECADI, 2008. Disponível em: http://portal.mec.gov.br/index.php?option=com_docman\&view=download\&alias=16690-politicanacional-de-educacao-especial-na-perspectiva-da-educacao-inclusiva-05122014\&Itemid=30192>. Acesso em: 12 dez. 2016.

É forçoso, portanto, reconhecer a existência de Normas Constitucionais, Leis, Decretos e Portarias no Brasil, que buscam garantir a pessoa portadores de necessidades especiais a proteção e socorro em quaisquer circunstâncias. Como Normas Constitucionais que fundamentam as orientações básicas para todas as iniciativas com vista a uma sociedade inclusiva encontram-se:

- CONSTITUIÇÃO FEDERAL DA REPÚBLICA FEDERATIVA DO BRASIL - promulgada em 05 de outubro de 1988.

- DECRETO LEGISLATIVO N 186, de 09 de julho de 2008 - Aprova o texto da Convenção sobre os Direitos das Pessoas com Deficiência e de seu Protocolo Facultativo, assinados em Nova Iorque, em 30 de março de 2007.

- DECRETO No 6.949, de 25 de agosto de 2009 - Promulga a Convenção Internacional sobre os Direitos das Pessoas com Deficiência e seu Protocolo Facultativo, assinados em Nova York, em 30 de março de 2007.

Neste estapa do estudo, apresentar-se-á algumas orientações básicas, estabelecidas no país, para a adequada condução dos sistemas de ensino para a área de Educação Especial.

Inicialmente, tem-se a Lei de Diretrizes e Bases da Educação Nacional (LDB), Lei no 9.394/96, que no artigo $4^{\circ}$, inciso III, estabelece que é dever do Estado com a educação escolar pública garantir o "atendimento educacional especializado gratuito aos educandos com deficiência, transtornos globais do desenvolvimento e altas habilidades ou superdotação, transversal a todos os níveis, etapas e modalidades, preferencialmente na rede regular de ensino" (Redação dada pela Lei no 12.796, de 2013).

Carneiro (2015, p. 121-123), destaca a existência de dificuldades e limitações para o atendimento as necessidades educativas específicas, considerando a complexidade que envolve todo o processo, e, principalmente, na medida em que requerem meios e apoios mais especializados para o que o aluno possa acessar regularmente o currículo. No entanto, o autor ressalta a importância e urgência no atendimento da questão, quando afirma: "estamos diante de um aluno especial e a escola tem o dever de atender, adequadamente, suas necessidades educacionais especiais" e, portanto, "a escola é que deve se adequar à recepção de todos os alunos e não os alunos à Escola".

Ainda buscando a LDB, encontra-se no capítulo destinado a Educação Especial, a seguinte afirmação:

Persp. online: hum. \& sociais aplicada., Campos dos Goytacazes, 19 (7), 10-22, 2017

seer.perspectivasonline.com.br 
Art. 58. Entende-se por educação especial, para os efeitos desta Lei, a modalidade de educação escolar oferecida preferencialmente na rede regular de ensino, para educandos com deficiência, transtornos globais do desenvolvimento e altas habilidades ou superdotação. (Redação dada pela Lei n ${ }^{\circ} 12.796$, de 2013)

$\S 1^{\circ}$ Haverá, quando necessário, serviços de apoio especializado, na escola regular, para atender às peculiaridades da clientela de educação especial.

$\S 2^{\circ} \mathrm{O}$ atendimento educacional será feito em classes, escolas ou serviços especializados, sempre que, em função das condições específicas dos alunos, não for possível a sua integração nas classes comuns de ensino regular.

$\S 3^{\circ} \mathrm{A}$ oferta de educação especial, dever constitucional do Estado, tem início na faixa etária de zero a seis anos, durante a educação infantil.

Percebe-se, portanto, a relevância do tema e a ressonância com o que está preconizado na Declaração Universal de Direitos Humanos (1949), marco inicial de Internacionalização dos direitos humanos, quando afirma:

Art. $1^{\circ}$ Todos os seres humanos nascem livres e iguais em dignidade e direitos e, dotados como estão de razão e consciência, deve comportar-se fraternamente uns com os outros.

Art. $2^{\circ}$ Toda pessoa tem todos os direitos e liberdades proclamados nesta declaração, sem distinção alguma de raça, cor, sexo, idioma, religião, opinião pública ou de qualquer outra índole, origem nacional ou social, posição econômica, nascimento ou qualquer outra condição.

Carneiro (2015, p. 608), com relação a este capítulo destinado a Educação Especial na LDB, compreende o mesmo como uma reafirmação do que já consta Constituição Federal de 1988, enquanto um princípio de igualdade de direitos, ou seja, "a própria inscrição do conceito de sociedade inclusiva em cujo o bojo estão os sistemas de ensino e a escola, com a responsabilidade intransferível de preparar espaços de aprendizagem sistematizada para TODOS".

$\mathrm{Na}$ esteira desse pensamento, tem-se no Estatuto da Criança e do Adolescente (ECA), Lei 8.069/90, enquanto um príncipio fundamental para a universalização do direito da criança e do adolescente, o artigo $3^{\circ}$ , que deterrmina:

A criança e o adolescente gozam de todos os direitos fundamentais inerentes à pessoa humana, sem prejuízo da proteção integral de que trata esta Lei, assegurando-se-lhes, por lei ou por outros, meios, todas as oportunidades e facilidades, a fim de lhes facultar o desenvolvimento físico, mental, moral, espiritual e social, em condições de liberdade e de dignidade.

Ao interpretar o referido artigo, o Promotor de Justiça Murillo José Digiácomo e a Professora Ildeara de Amorim Digiácomo (2013, p. 5), ressaltam que:

Apesar de dizer aparentemente o óbvio, o presente dispositivo traz uma importante inovação em relação à sistemática anterior ao ECA, na medida em que reconhece a criança e o adolescente como sujeitos de direitos, e não meros "objetos" da intervenção estatal. Tal disposição é também reflexo do contido no art. $5^{\circ}$, da $\mathrm{CF} / 88$, que ao conferir a todos a igualdade em direitos e deveres individuais e coletivos, logicamente também os estendeu a crianças e adolescentes.

Buscando garantir o atendimento especializado ao aluno portador de demandas educacionais específicas, a LDB estabelece ainda em seu artigo 59 que:

Os sistemas de ensino assegurarão aos educandos com deficiência, transtornos globais do desenvolvimento e altas habilidades ou superdotação: (Redação dada pela Lei $n^{\circ} 12.796$, de 2013)

I - currículos, métodos, técnicas, recursos educativos e organização específicos, para atender às suas necessidades;

Persp. online: hum. \& sociais aplicada., Campos dos Goytacazes, 19 (7), 10-22, 2017

seer.perspectivasonline.com.br 
II - terminalidade específica para aqueles que não puderem atingir o nível exigido para a conclusão do ensino fundamental, em virtude de suas deficiências, e aceleração para concluir em menor tempo o programa escolar para os superdotados;

III - professores com especialização adequada em nível médio ou superior, para atendimento especializado, bem como professores do ensino regular capacitados para a integração desses educandos nas classes comuns;

IV - educação especial para o trabalho, visando a sua efetiva integração na vida em sociedade, inclusive condições adequadas para os que não revelarem capacidade de inserção no trabalho competitivo, mediante articulação com os órgãos oficiais afins, bem como para aqueles que apresentam uma habilidade superior nas áreas artística, intelectual ou psicomotora;

V - acesso igualitário aos benefícios dos programas sociais suplementares disponíveis para o respectivo nível do ensino regular.

Configura-se, portanto, como preceito legal, que os sistemas de ensino garantam aos estudantes currículo, métodos, recursos e organização específicos para atender às suas demandas, assim como, "assegura a terminalidade específica àqueles que não atingiram o nível exigido para a conclusão do ensino fundamental, em virtude de suas deficiências; e assegura a aceleração de estudos aos superdotados para conclusão do programa escolar". (MEC/SECADI, 2013, p. 3)

Pode-se citar, ainda como de profunda relevância, o documento elaborado, em 2008, pelo Grupo de Trabalho da Política Nacional de Educação Especial do Ministério da Educação (MEC) que estabelece a "Política Nacional de Educação Especial na Perspectiva da Educação Inclusiva", que enquanto uma política pública promotora de uma educação de qualidade para todos os alunos, estabeleceu um conjunto de normas e orientações com o seguinte objetivo:

assegurar a inclusão escolar de alunos com deficiência, transtornos globais do desenvolvimento e altas habilidades/superdotação, orientando os sistemas de ensino para garantir: acesso ao ensino regular, com participação, aprendizagem e continuidade nos níveis mais elevados do ensino; transversalidade da modalidade de educação especial desde a educação infantil até a educação superior; oferta do atendimento educacional especializado; formação de professores para o atendimento educacional especializado e demais profissionais da educação para a inclusão; participação da família e da comunidade; acessibilidade arquitetônica, nos transportes, nos mobiliários, nas comunicações e informação; e articulação intersetorial na implementação das políticas públicas. (BRASIL, 2008, p. 14)

Todas essas iniciativas têm, segundo Rodrigues e Alves (2014), colaborado para suscitar pleitos de tecnologia assistivas em larga escala, principalmente, considerando os recursos oferecidos pelo computador no atendimento a alunos portadores de deficiência. Kleina (2012, p. 32) ressalta anda que, atualmente, existe uma "diversidade de recursos tecnológicos. (...) Conhecer esses recursos é um desafio dos profissionais da educação". Afirma ainda que "quando usamos uma ferramenta ou um recurso específico para um aluno que possui uma limitação, estamos fazendo uso de uma tecnologia assistivas".

\subsection{Definição de Tecnologia Assistiva}

\subsubsection{Origem do termo}

Criado em 1988, o termo Assistive Technology, compõe junto com outras leis americanas, o ADA (American with Disabilities Act), órgão responsável pela regulação dos direitos dos cidadãos com deficiência nos EUA, assim como por fornecer o aparato legal dos fundos públicos para aquisição de recursos para os que necessitam.

O termo Assistive Technology, traduzido no Brasil como Tecnologia Assistiva, foi criado oficialmente em 1988 como importante elemento jurídico dentro da legislação norteamericana, conhecida como Public Law 100-407, que compõe, com outras leis, o ADA American with Disabilities Act. Este conjunto de leis regula os direitos dos cidadãos com

Persp. online: hum. \& sociais aplicada., Campos dos Goytacazes, 19 (7), 10-22, 2017

seer.perspectivasonline.com.br 
deficiência nos EUA, além de prover a base legal dos fundos públicos para compra dos recursos que estes necessitam. Houve a necessidade de regulamentação legal deste tipo de tecnologia, a TA, e, a partir desta definição e do suporte legal, a população norteamericana, de pessoas com deficiência, passa a ter garantido pelo seu governo o benefício de serviços especializados e o acesso a todo o arsenal de recursos que necessitam e que venham favorecer uma vida mais independente, produtiva e incluída no contexto social geral. (GALVÃO FILHO, 2009, p. 208 apud BERSCH, 2005)

Mara Lúcia Sartoretto e Rita Bersch $(2017$, p. 1) definem tecnologia assistiva como "um termo ainda novo, utilizado para identificar todo o arsenal de Recursos e Serviços que contribuem para proporcionar ou ampliar habilidades funcionais de pessoas com deficiência e consequentemente promover Vida Independente e Inclusão".

$\mathrm{Na}$ esteira desse pensamento, o professor Galvão Filho (2009, p. 207) mesmo reconhecendo ser a tecnologia assistiva um conceito "ainda em pleno processo de construção e inocação", afirma que o uso de recursos de Tecnologia Assistiva, "remonta aos primórdios da história da humanidade ou até mesmo da préhistória. Qualquer pedaço de pau utilizado como uma bengala improvisada, por exemplo, caracteriza o uso de um recurso de Tecnologia Assistiva".

\subsubsection{Tecnologia Assistiva no Brasil}

No Brasil o termo foi traduzido como Tecnologia Assistiva, com derivações "como adaptações, ajudas técnicas, autoajudas e ajudas de apoio". (KLEINA, 2012, p. 33)

O Decreto $n^{\circ} 5.296 / 2004$ criou o Comitê de Ajudas Técnicas (CAT, 2008), no entanto, este somente foi instituído em 2006, no âmbito da Secretaria Especial dos Direitos Humanos da Presidência da República. Criado com a finalidade principal de aperfeiçoar, dar transparência e legitimidade ao desenvolvimento da Tecnologia Assistiva no Brasil, por meio de políticas públicas, define o termo como:

uma área do conhecimento, de característica interdisciplinar, que engloba produtos, recursos, metodologias, estratégias, práticas e serviços que objetivam promover a funcionalidade, relacionada à atividade e participação, de pessoas com deficiência, incapacidades ou mobilidade reduzida, visando sua autonomia, independência, qualidade de vida e inclusão social. (BRASIL/CAT, 2009)

O CAT, conforme estabelece o artigo 66 do referido decreto, é responsável por:

I - estruturação das diretrizes da área de conhecimento;

II - estabelecimento das competências desta área;

III - realização de estudos no intuito de subsidiar a elaboração de normas a respeito de ajudas técnicas;

IV - levantamento dos recursos humanos que atualmente trabalham com o tema; e

$\mathrm{V}$ - detecção dos centros regionais de referência em ajudas técnicas, objetivando a formação de rede nacional integrada.

O Decreto no 5.296/2004 define "ajudas técnicas" como: "produtos, instrumentos, equipamentos ou tecnologia adaptados ou especialmente projetados para melhorar a funcionalidade da pessoa portadora de deficiências ou com mobilidade reduzida, favorecendo a autonomia pessoal, total ou assistida". (BRASIL, 2004)

Encontra-se, também com destaque, no Decreto a questão acessibilidade. $\mathrm{O}$ artigo $8^{\circ}$ define que para os fins de acessibilidade, deve-se considerar:

I - acessibilidade: condição para utilização, com segurança e autonomia, total ou assistida, dos espaços, mobiliários e equipamentos urbanos, das edificações, dos serviços de

Persp. online: hum. \& sociais aplicada., Campos dos Goytacazes, 19 (7), 10-22, 2017

seer.perspectivasonline.com.br 
transporte e dos dispositivos, sistemas e meios de comunicação e informação, por pessoa portadora de deficiência ou com mobilidade reduzida;

II - barreiras: qualquer entrave ou obstáculo que limite ou impeça o acesso, a liberdade de movimento, a circulação com segurança e a possibilidade de as pessoas se comunicarem ou terem acesso à informação (...);

III - elemento da urbanização: qualquer componente das obras de urbanização, tais como os referentes à pavimentação, saneamento, distribuição de energia elétrica, iluminação pública, abastecimento e distribuição de água, paisagismo e os que materializam as indicações do planejamento urbanístico;

IV - mobiliário urbano: o conjunto de objetos existentes nas vias e espaços públicos, superpostos ou adicionados aos elementos da urbanização ou da edificação, de forma que sua modificação ou traslado não provoque alterações substanciais nestes elementos, tais como semáforos, postes de sinalização e similares, telefones e cabines telefônicas, fontes públicas, lixeiras, toldos, marquises, quiosques e quaisquer outros de natureza análoga;

V - ajuda técnica: os produtos, instrumentos, equipamentos ou tecnologia adaptados ou especialmente projetados para melhorar a funcionalidade da pessoa portadora de deficiência ou com mobilidade reduzida, favorecendo a autonomia pessoal, total ou assistida;

VI - edificações de uso público: aquelas administradas por entidades da administração pública, direta e indireta, ou por empresas prestadoras de serviços públicos e destinadas ao público em geral;

VII - edificações de uso coletivo: aquelas destinadas às atividades de natureza comercial, hoteleira, cultural, esportiva, financeira, turística, recreativa, social, religiosa, educacional, industrial e de saúde, inclusive as edificações de prestação de serviços de atividades da mesma natureza;

VIII - edificações de uso privado: aquelas destinadas à habitação, que podem ser classificadas como unifamiliar ou multifamiliar; e

IX - desenho universal: concepção de espaços, artefatos e produtos que visam atender simultaneamente todas as pessoas, com diferentes características antropométricas e sensoriais, de forma autônoma, segura e confortável, constituindo-se nos elementos ou soluções que compõem a acessibilidade. (BRASIL, 2004, grifo nosso)

Outro ponto a ser destacado no referido Decreto, é o artigo 47, que determina como sendo “obrigatória a acessibilidade nos portais e sítios eletrônicos da administração pública na rede mundial de computadores (internet), para o uso das pessoas portadoras de deficiência visual, garantindo-lhes o pleno acesso às informações disponíveis". (BRASIL, 2004)

Galvão Filho (2009, p. 217) em seus estudos e pesquisas sobre Tecnologia Assistiva, apresenta um destaque para acessibilidade enquanto desenho industrial. Para o autor, o conceito concebe

a ideia de que todas as realidades, ambientes, recursos, etc., na sociedade humana, devem ser concebidos, projetados, com vistas à participação, utilização e acesso de todas as pessoas. Essa concepção, portanto, transcende a ideia de projetos específicos, adaptações e espaços segregados, que respondam apenas a determinadas necessidades.

Finalizando os estudos de natureza teórica e preliminar sobre o termo Tecnologia Assistiva no Brasil, apresenta-se a definição apresentada pela Secretaria de Educação Especial do Ministério da Educação, quando diz que as Tecnologias Assistivas representam todos os recursos (todo e qualquer item, equipamento ou parte dele, produto ou sistema fabricado em série ou sob medida utilizado para aumentar, manter ou melhorar as capacidades funcionais das pessoas com deficiência) e serviços (profissionais de diversas áreas que auxiliam diretamente uma pessoa com deficiência a selecionar, obter ou usar um instrumento de tecnologia assistiva).

\section{CONSIDERAÇÕES FINAIS}

Acredita-se após o caminho percorrido de estudos, análises e pesquisas teóricas ter sido possível avançar em nossas análises e socializar nossas discussões, aprofundando e ampliando nosso campo de visibilidade, a partir do resgate real de quadros de referência teórica aqui apresentados sob o tema Tecnologia Assistiva.

Persp. online: hum. \& sociais aplicada., Campos dos Goytacazes, 19 (7), 10-22, 2017

seer.perspectivasonline.com.br 
Os autores são unânimes em discorrer que mesmo tendo origem em 1988, ainda se apresenta, conforme afirma Galvão Filho (2009), como em "pleno processo de construção e sistematização". Muitas são as possibilidades, recursos, estratégias e serviços que podem ser utilizados por professores e disponibilizados em sala de aula, para o atendimento escolar, considerando as demandas de cada aluno portadores de necessidades educacionais especiais.

\section{REFERÊNCIAS}

BERSCH, Rita. Introdução à tecnologia assistiva. Porto Alegre: CEDI, 2013. Disponível em: $<$ http://www.assistiva.com.br/Introducao_Tecnologia_Assistiva.pdf $>$. Acesso em 13 nov. 2016.

BRASIL. Subsecretaria Nacional de Promoção dos Direitos da Pessoa com Deficiência. Comitê de Ajudas Técnicas. Tecnologia Assistiva. Brasília: CORDE, 2009. Disponível em: $<$ http://www.pessoacomdeficiencia. gov.br/app/publicacoes/tecnologia-assistiva>. Acesso em 06 dez. 2016.

BRASIL. Decreto $\mathrm{n}^{\mathrm{o}} 5.296$ de 2 de dezembro de 2004. Regulamenta as Leis $\mathrm{n} 10.048$, de 8 de novembro de 2000, que dá prioridade de atendimento às pessoas que especifica, e 10.098 , de 19 de dezembro de 2000, que estabelece normas gerais e critérios básicos para a promoção da acessibilidade das pessoas portadoras de deficiência ou com mobilidade reduzida, e dá outras providências. Brasília: MEC. Disponível em: < http://portal.mec.gov.br/seesp/arquivos/pdf/decreto\%205296 -2004.pdf>. Acesso em: 10 jan. 2017.

BRASIL. Decreto ${ }^{\circ}$ 6.949, de 25 de agosto de 2009. Promulga a Convenção Internacional sobre os Direitos das Pessoas com Deficiência e seu Protocolo Facultativo, assinados em Nova York, em 30 de março de 2007. Diário Oficial [da] República Federativa do Brasil, Poder Executivo, Brasília, DF, 26 ago. 2009. Disponível em: <http://www.planalto.gov.br/ccivil_03/_ato2007-2010/2009/decreto/d6949.htm>. Acesso em: 09 mar. 2017.

BRASIL. Estatuto da Criança e do Adolescente. Lei número 8069, de 13 de julho de 1990.

BRASIL. Lei de Diretrizes e Bases da Educação. Lei no 9.394/96, de 20 de dezembro de 1996. Disponível em: <http://www.planalto.gov.br/ccivil_03/leis/L9394.htm>. Acesso em: 09 set. 2016.

BRASIL. Política Nacional de Educação Especial na Perspectiva da Educação Inclusiva. Brasília: MEC/SECADI. 2013. Disponível em: <http://portal.mec.gov.br/index.php?option=com_docman\&view= download\&alias=16690-politica-nacional-de-educacao-especial-na-perspectiva-da-educacao-inclusiva05122014\&Itemid=30192>. Acesso em: 18 jan. 2017.

BRASIL. Secretaria de Educação Especial. Política Nacional de Educação Especial na Perspectiva da Educação Inclusiva. Brasília, DF: MEC/SEESP, 2008. Disponível em: $<$ http://portal.mec.gov.br/arquivos/pdf/politicaeducespecial.pdf $>$. Acesso em: 18 dez. 2016.

CAPOVILLA, Fernando César. Pesquisa e desenvolvimento de novos recursos tecnológicos para educação especial: boas novas para pesquisadores, clínicos, professores, pais e alunos. Em Aberto, v. 13, n. 60, 1993. Disponível em: <http://www.ip.usp.br/lance/artigos/1993_capovilla.pdf>. Acesso em: 13 nov. 2016.

CARNEIRO, Moaci Alves. LDB fácil: leitura crítica-compreensiva, artigo a artigo. 23. ed. revista e ampliada. Petrópolis, RJ: Vozes, 2015.

DECLARAÇÃO UNIVERSAL DOS DIREITOS HUMANOS. Assembleia Geral das Nações Unidas em Paris. 10 dez. 1948. Disponível em: <http://www.dudh.org.br/wpcontent/uploads/2014/12/dudh.pdf $>$. Acesso em: 26 jan. 2017. 
DIGIÁCOMO, Murillo José; DIGIÁCOMO, Ildeara Amorim. Estatuto da criança e do adolescente: anotado e interpretado. 6. ed. Curitiba: Ministério Público do Estado do Paraná. Centro de Apoio Operacional das Promotorias da Criança e do Adolescente, 2013.

GALVÃO FILHO, T. A. et al. Conceituação e estudo de normas. In: BRASIL, Tecnologia Assistiva. Brasília: CAT/SEDH/PR, 2009, p. 13-39.

GALVÃO FILHO, T. A. A tecnologia assistiva: de que se trata? In: MACHADO, G. J. C.; SOBRAL, M. N. (Orgs.). Conexões: educação, comunicação, inclusão e interculturalidade. 1. ed. Porto Alegre: Redes Editora, p. 207-235, 2009. Disponível em: <http://www.galvaofilho.net/assistiva.pdf $>$. Acesso em: 12 dez. 2016.

IBGE. Censo demográfico 2010: características gerais da população, religião e pessoas com deficiência. Ministério do Planejamento, Orçamento e Gestão. Rio de Janeiro: Instituto Brasileiro de Geografia e Estatística, 2012. 215 p. Disponível em: <http://biblioteca.ibge.gov .br/visualizacao/periodicos/94/cd_2010_religiao_deficiencia.pdf > . Acesso em: 13 dez. 2016.

KLEINA, Cláudio. Tecnologia assistiva em educação especial e educação inclusiva. Curitiba: InterSaberes, 2012. (Série Inclusão Escolar)

RODRIGUES, Patrícia Rocha; ALVES, Lynn Rosalina Gama. Tecnologia assistiva: uma revisão do tema. HOLOS, [S.1.], v. 6, p. 170-180, jan. 2014. ISSN 1807-1600. Disponível em: $<$ http://www2.ifrn.edu.br/ojs/index.php/HOLOS/article/view/1595/765>. Acesso em: 18 dez. 2016.

SARTORETTO, Mara Lúcia; BERSCH, Rita. Assistiva: tecnologia e educação. 2017. Disponível em: $<\mathrm{http}: / /$ www.assistiva.com.br/tassistiva.html $>$. Acesso em: 22 jan. 2017.

SODRÉ, Muniz. Reinventando @ cultura: a comunicação e seus produtos. 3. ed. Petrópolis, RJ: Vozes, 1999.

World Health Organization; The World Bank. Relatório mundial sobre a deficiência. Tradução por Lexicus Serviços Linguísticos. São Paulo: SEDPcD, 2012. Disponível em: $<$ http://www.pessoacomdeficiencia.sp.gov.br/usr/share/documents/RELATORIO_MUNDIAL_ COMPLETO.pdf>. Acesso em: 13 nov. 2016. 